\title{
$(12.00 .08)$
}

\section{Соколов И.А.}

«ИСТОРИА ПРАВОВОГО РЕГУЛИРОВАНИЯ

УЧАСТИЯ ПРОКУРОРА В ОБЕСПЕЧЕНИИ

ИНФОРМАЦИОННОЙ БЕВОПАСНОСТИ

ГОСУДАРСТВА॥ (ПОСВАШАЕТСЯ 300-ЛЕТИЮ

ПРОКУРАTУРЫ РОССИИ)

\section{Sokolov I.A. \\ "THE HISTORY OF LEGAL REGULATION OF THE PARTICIPATION OF THE PROSECUTOR IN ENSURING THE INFORMATION SECURITY OF THE STATE" (DEDICATED TO THE 300TH ANNIVERSARY OF THE RUSSIAN PROSECUTOR'S OFFICE)}

Статья рассматривает историю зарождения и развития института участия отечественной прокуратуры в обеспечении информационной безопасности государства, соответствующие периоды становления названного направления прокурорской деятельности и полномочия прокуратуры на различных этапах развития надзорного органа, а также соответствующие нормативные правовые документы по вопросам указанной деятельности. Автором обосновывается исторически-обусловленная необходимость включения в Доктрину информационной безопасности органа прокуратуры как одного из важнейших субъектов обеспечения информационной безопасности государства.

Ключевые слова: прокуратура, закон, прокурорский надзор, история, информационная безопасность государства.

The article examines the history of the origin and development of the institution of participation of the domestic prosecutor's office in ensuring the information security of the state, the corresponding periods of the formation of the named direction of prosecutorial activities and the powers of the prosecutor's office at various stages of the development of the supervisory body, as well as the relevant regulatory legal documents on these activities. The author substantiates the historically conditioned need to include the prosecutor's office in the Doctrine of Information Security as one of the most important subjects of ensuring the information security of the state.

Keywords: prosecutor's office, law, prosecutor's supervision, history, information security of the state.

Человек на современной стадии развития общества каждый день является производителем, распространителем и получателем информации.

При этом информация всегда сопровождала человека с того момента, как он получил способность разумно мыслить и преобразовывать мир вокруг себя, соз- дав ноосферу, в которой выделились три основных сферы человеческой деятельности: производственная, технологическая и информационная [1].

Исторически информация о месторасположении племени, рода, города, их стратегических объектов, имуществе, количестве жителей и других данных имела 
для человека зачастую жизненно важное значение, в связи с чем появилась необходимость ограничения и защиты такой информации

Шифры активно использовали древние цивилизации Вавилона, Египта, Греции, Рима, Китая и Индии [2, С. 14].

Древнеславянские племена для обмена информацией использовали различного рода знаки и сигналы. Так, старейшина деревни объявлял жителям о смерти одного из сородичей посредством черного жезла, который носили из одного двора поселения в другой [3, С. 15].

В средние века в Европе с целью защиты важнейших данных применяются тайнопись, использование рунических символов. Система шифрования использовалась и алхимиками для засекречевания важных частей формул получения философского камня [2, С. 32-34].

В 20-е годы XIII века в Российской империи формируется нормативная база, регламентирующая порядок обращения с информацией ограниченного доступа, а также закладывающая основы секретного делопроизводства.

Так, 13 января 1724 года монархом издан именной Указа Сенату «О написании секретных дел в партикулярных письмах», 16 января 1724 г. - Указ «О поручении секретных дел в Сенате благонадежным людям». Правительствующим Сенатом 05 марта 1724 года издается Приказ «О надписях на пакетах, в которых секретные дела» [4].

Практически в то же время, 12 января 1722 года, Указом Петра I [5] определяется, что «Надлежит быть при Сенате Генерал-Прокурору и Обер-прокурору, также во всякой Коллегии по Прокурору, которые должны будут рапортовать ГенералПрокурора». С этого момента и отсчитывает свою историю отечественная прокуратура.

Полномочия Генерал-Прокурора утверждаются именным указом от 27.04.1722 года [6], в котором и закрепляется основная функция нововведенной должности - надзор за исполнением указов российского императора в Сенате.

Несмотря на отмечаемую исследователями малочисленность состава российской прокуратуры [7, С. 20], исходя из анализа общих полномочий созданного надзорного ведомства, полагаем, все же можно сделать вывод, что контроль за исполнением Сенатом актов, регламентирующих обеспечение информационной безопасности государства, должен был быть осуществлен Генерал-Прокурором, а соблюдение необходимых требований по защите государственной информации коллегиями согласно Указу от 12 января 1722 года проверяться прокурорами.

С этого момента вовлеченность органов прокуратуры в вопросы обеспечения информационной безопасности государства на каждом этапе развития надзорного органа являлась неизменной.

После смерти Петра I в эпоху дворцовых переворотов роль и полномочия прокуратуры каждый раз несистемно переформатируются в зависимости от предпочтений каждого нового государя. И только с проведением административной реформы Екатериной II начинается новый этап дальнейшего поступательного развития отечественной прокуратуры.

Надзорная роль прокурора в этот период значительно укрепляется.

В соответствии с манифестом от 15 декабря 1763 года Сенат подразделяется на 6 департаментов. Во главе первого департамента становится Генерал-прокуpop [8]. C 1767 года при остальных департаментах состоят обер-прокуроры [9].

Немногим ранее, 25 февраля 1762 года, при Сенате образовывается (еще Петром III) Тайная экспедиция, являющаяся по сути полной преемницей Тайной канцелярии, учрежденной при Петре I. Во главе Тайной экспедиции находится генерал-прокурор Сената [10]. В функции Тайной экспедиции при Сенате входили осуществление политического сыска, осуществление контрразведывательных функций, борьба со шпионами, а также уголовное преследование лиц, уличенных в политической измене, разглашении секретных данных, непристойном рассуждении о монархе.

Так, например, в результате работы Тайной экспедиции путем дешифрования скрытой переписки в 1792 г. был арестован один из руководителей масонского движения в России Н.И. Новиков - известный писатель, литератор и публицист. Официальной причиной ареста Н.И. Новикова явилось печатание церковных книг в принадлежавшей ему типографии, а это не допускалось, поскольку являлось исключительным правом Священного Синода [11].

Проводимая одновременно с этим губернская реформа Екатерины II определяет при наместническом или губернском правлении, а также губернском магистрате должности Губернского прокурора и прокурора соответственно. Надзорные полномочия прокуроров, а также штат на местах значительно расширяются.

Как видно из текста Учреждения для 
управления губерний Всероссийской империи от 07 ноября 1775 года в обязанности Губернского прокурора входило сообщать наместническому или губернскому правлению сведения о таких обстоятельствах, которые в наше время можно было смело расценить как политическую пропаганду (или контрпропаганду) или информационную войну: буде где в наместничестве есть непослушание, или ропот, о нарушении правил благочиния и о всяком причиняющемся многим соблазне, законам противном поступке, вине, или преступлении, о запрещенной торговле, или о помешательстве законам противном дозволенной торговле, о нарушении тишины, о нарушении в верности присяги, о казенном и общественном ущербе... [12]

Взошедший на трон в 1796 году Павел I кардинальным образом роль прокуратуры не изменяет (за исключением частичного сокращения состава губернских прокуроров). Наоборот полномочия надзорного органа расширяются: генерал-прокуроры того времени не только сосредоточили в своих руках надзор за деятельностью Сената и исполнением законов и воли монарха в империи, но соединяли его с исполнением иных обязанностей, главной из которых было руководство Тайной экспедицией Сената [7, С. 38].

В сфере вопросов, которые условно можно обозначить как обеспечение информационной безопасности, в период царствования Павла I полномочия прокурора включают в себя: осуществление цензуры периодической печати, наблюдение за иностранцами (в том числе выдача иностранных паспортов и виз), руководство пограничной службой (через которую проходила вся внешняя секретная корреспонденция), занятие делами вероисповеданий [14].

При Александре I должность генералпрокурора совмещается с должностью министра юстиции, органы прокуратуры входят фактически в состав министерства юстиции. Одновременно с этим впервые в истории на орган прокуратуры возлагается надзор за следствием [14].

Как отмечает А.В. Еремин: «Подводя итог развитию отечественной прокуратуры в первой половине XIX в., следует сказать, что это было время кардинального изменения ее характера. Те особенности, которые были заложены в институт прокуратуры в XVIII в., получили полное раскрытие, сформировав новый облик прокуратуры» $[7$, C. 38].

Значительные изменения системы полномочий отечественной прокуратуры приходят с реформами (прежде всего земской и судебной) императора Александра II.

По результатам судебной реформы роль прокурора фактически полностью свелась к уголовному преследованию, осуществлению обвинения в судах и надзору за следствием. Имевшиеся общенадзорные полномочия прокурора практически полностью упразднены [15].

В качестве новеллы уголовно-процессуального блока судебной реформы можно отметить возложение на прокуроров обязанности по осуществлению судебного преследования по государственный преступлениям. Предварительное следствие по таким делам производилось членом судебной палаты при непосредственном присутствии прокурора палаты. Он же составлял обвинительный акт и поддерживал обвинение в суде [16].

Напомним, что в то время к категории таких преступлений причислялись, в том числе, «составление и распространение письменных или печатных объявлений, воззваний, или же сочинений, или изображений с целью возбудить к бунту или явному неповиновению власти верховной», государственная измена (включающая в себя разглашение государственной тайны иностранным державам) [17].

В связи с появлением революционного («народнического») движения увеличивается число «политических» процессов, обвинение по которым поддерживается прокурорами.

К числу таких можно отнести так называемый «Большой процесс» (или «Процесс 193-х») по обвинению участников движения «Хождение в народ» за осуществление революционной пропаганды. Государственное обвинение поддерживалось Товарищем обер-прокурора Уголовного кассационного департамента Сената Желяховским В.А [18].

Внутриполитический курс следующего императора - Александра III, направленный на ограничение реформ своего предшественника и получивший название «контрреформы», сказывается и на полномочиях прокуратуры, объем которых в известной степени сокращается (так, у полиции и жандармерии возникает право без санкции прокурора производить обыски и выемки во всех без исключения помещениях, задержания на срок до двух недель по подозрению в причастности к государственным преступлениям) [19].

В связи с проводимой Александром III политикой «закручивания гаек» к ведению прокуратуры частично возвращаются определенные вопросы в сфере цензуры.

Например, в соответствии с новыми 
«Временными правилами о печати» от 27 августа 1882 г. решение об окончательном прекращении повременного издания (с запрещением редактору впоследствии издавать другое) стало приниматься Верховной комиссией по печати, в состав которой входили министры внутренних дел, юстиции и народного просвещения, а также обер-прокурор Святейшего Синода, а также министры и главноуправляющие тех ведомств, которыми возбуждались подобные иски [3, С. 323].

В советские годы после недолгого упразднения надзорного ведомства с 1922 года происходит последующая его реставрация в той концепции, которая, в известном смысле, сохраняется в нашем государстве и по сей день. Впервые на законодательном уровне выделяется в самостоятельную отрасль надзор за законностью действий всех органов власти, хозяйственных учреждений, общественных и частных организаций (так называемый «общий надзор»), в прокуратуру опять «возвращаются» функции по поддержанию государственного обвинения, надзора за следствием, а также надзора за правильностью содержания заключенных под стражей [20].

Вторым Съездом Советов СССР 31 января 1924 г. утверждена Конституция (Основной Закон) СССР, в которой закреплены полномочия Прокурора Верховного Суда Союза Советских Социалистических республик [21].

Стоит отметить, что отдельно в Основном законе СССР был закреплен надзор за законностью действий Объединенного Государственного Политического Управления (ОГПУ), осуществляемый Прокурором Верховного Суда СССР.

В задачи ОГПУ в то время входят, в том числе, предупреждение и подавление контрреволюционных проявлений, охрана государственных тайн и борьба со шпионажем в любых его проявлениях [22].

Таким образом, на высшем государственном нормативном уровне закрепляется особая роль прокуратуры по надзору за обеспечением безопасности государства, в том числе, его защищенности от внутренних и внешних информационных угроз.

Достигнутые результаты в формировании органов прокуратуры в последующем получили закрепление в Конституции (Основном Законе) СССР, принятой VIII Чрезвычайным съездом Советов СССР 5 декабря 1936 года [23].

В годы Великой Отечественной войны в духе военного времени происходит ужесточение ответственности за нарушения военного законодательства. Так, Прокурор СССР и Народный комиссар внутренних дел СССР 26 июня 1941 г. издали приказ № 159/595 «О квалификации нарушений правил и распоряжений о местной противовоздушной обороне», согласно которому злостное нарушение распоряжений по светомаскировке влекло за собой привлечение к уголовной ответственности, а если оно было использовано на оказание содействия врагу, то эти действия следовало квалифицировать как измена Родине. Согласно приказу Народного комиссара юстиции СССР и Прокурора СССР от 27 июня 1941 г. № 104/64 предлагалось передавать все дела о террористической агитации на рассмотрение военных трибуналов войск НКВД [7, С. 87].

Заключительный этап развития советской прокуратуры связан с принятием Конституции СССР 1977 года [24] и Конституции РСФСР 1978 года [25], а также принятием Закона СССР от 30.11.1979 N 1162-Х «О прокуратуре СССР» [26], в соответствии с которыми определялись организация и порядок деятельности органов прокуратуры.

Указанные документы закрепляют возросшее значение прокуратуры в тот период.

Принятие Федерального закона от 17.11.1995 № 168-Ф3 «О прокуратуре Российской Федерации» [27] ознаменовало собой новую эпоху развития отечественного надзорного органа.

Трансформировалась, но осталась важной роль участия прокурора в обеспечении информационной безопасности государства. Наряду с классическими формами надзорных полномочий в указанной области с учетом развития цифровых технологий, появления новых видов информационных угроз появляются и новые формы прокурорской деятельности.

Как можно увидеть, на протяжении всей истории прокуратуры с самого момента ее возникновения прокурор занимал видное место в обеспечении государственной безопасности, в том числе защиты государства от внутренних и внешних информационных угроз. Такое же значительное положение в этой сфере закреплено за прокурором и на текущем этапе развития надзорного ведомства.

Однако, в настоящее время органы прокуратуры не включены в перечень субъектов обеспечения информационной безопасности, закрепленный в Доктрине информационной безопасности Российской Федерации (далее - Доктрина информационной безопасности) [28].

С учетом проведенного исследования 
и выявления исторически-обусловленной роли надзорного ведомства в указанном вопросе предполагается целесообразным нормативное закрепление в Доктрине информационной безопасности прокуратуры как одного из важнейших звеньев в системе субъектов обеспечения информационной безопасности государства.
Сам же институт участия прокурора в обеспечении информационной безопасности государства с учетом богатой истории его появления и развития является перспективным для проведения дальнейших научных исследований.

\section{Литература}

1. Манжуева О.Н. Феномен информационной безопасности: сущность и особенности: дис. ... докт. философ. наук: 09.00.11. - Улан-Удэ, 2015.

2. История защиты информации в зарубежных странах: учебное пособие/А.В. Бабаш, Д.А. Ларин. - М.: РИОР: ИНФРА-М, 2020.

3. Органы профессионального сыска и иные субъекты информационной безопасности Российской империи: монография. / Яковец Е.Н. - М.: Юрлит информ, 2012.

4. Полное собрание законов Российской империи. Собрание первое. 16491825 гг: в 48 т. (ПСЗРИ-1). СПб., 1830. Т. 6 . №№ $4409,4418,4481$.

5. Полное собрание законов Российской империи. Собрание первое. 16491825 гг.: в 48 т. (ПСЗРИ-1). СПб., 1830. Т. 6. № 3877.

6. Полное собрание законов Российской империи. Собрание первое. 16491825 гг.: в 48 т. (ПСЗРИ-1). СПб., 1830. Т. 6. № 3979.

7. История отечественной прокуратуры: учебное пособие / А. В. Ерёмин. Санкт-Петербург: Санкт-Петербургский юридический институт (филиал) Университета прокуратуры Российской Федерации, 2018.

8. Манифест от 15 декабря 1763 г. «Об учреждении в Сенате, в Юстиции, Вотчинной и Ревизион-Коллегиях Департаментов; о разделении по оным дел» // СПС Гарант

9. Полное собрание законов Российской империи. Собрание первое. 1649-1825 гг.: в 48 т. (ПСЗРИ-1). СПб., 1830. Т. 18. № 12932.

10. Карпенко С.В. Михаил Хрущев, Степан Шешковский и «преображенье» Тайной канцелярии в Тайную экспедицию/С.В. Карпенко//Новый исторический вестник. 2010. № 3. С. 57-94.

11. Органы профессионального сыска и иные субъекты информационной безопасности Российской империи: монография / Яковец Е.Н. - М.: Юрлит информ, 2012. - С. 181

12. Полное собрание законов Российской империи. Собрание первое. 1649-1825 гг.: в 48 т. (ПСЗРИ-1). СПб., 1830. Т. 20. № 14392.

13. О поступании ему в отправлении сей должности по инструкциям и указам; о бытии в его ведении Тайной экспедиции и Комиссии о сочинении проекта нового уложения и об определении Государственного казначея для управления Казенной частью: указ именной, данный генерал-прокурору 4 дек. 1796 г. // ПСЗРИ-1. Т. 24. № 17610 .

14. Полное собрание законов Российской империи. Собрание первое. 1649-1825 гг.: в 48 т. (ПСЗРИ-1). СПб., 1830. Т. 27. № 20552.

15. История российской прокуратуры: курс лекций / Д.В. Колыхалов; Ун-т прокуратуры Рос. Федерации. - М., 2018. - 104 с.

16. Судебные уставы 20 ноября 1864 г. за пятьдесят лет / В 2-х тт. и дополн. том. - Пг., 1914. - 786+831+191 с.

17. Уложение о наказаниях уголовных и исправительных, с приведением статей других томов Свода законов, на которые сделаны ссылки и указания в этом уложении (изд. 1866 г.) // URL: https://dlib.rsl.ru/01003543887, дата обращения 30.10 .2021

18. Государственные преступления в России в XIX веке: сб. полит. процессов и др. материалов, относящихся к истории революц. и оппозиц. движений в России / Сост. под ред. [и с предисл.] Б. Базилевского (В. Богучарского). - СПб., 1904 - 1906. // URL: https:// elib.shpl.ru/ru/nodes/8400-t-3-protsess-193-h-spb-1904-russkayaistoricheskaya-biblioteka-7\#mode/inspect/page/7/zoom/4, дата обращения 30.10.2021.

19. Положение о мерах к охранению государственного порядка и общественного спокойствия: положение Комитета министров, высочайше утвержденное 14 авг. 1881 г. // ПСЗРИ-3. Т. 1. № 350.

20. Постановление ВЦИК от 28.05.1922 «Положение о прокурорском надзоре» // СПС КонсультантПлюс.

21. Конституция (Основной Закон) Союза Советских Социалистических Республик (утверждена резолюцией II-го Съезда Советов Союза ССР от 31 января 1924 г.) // СПС Гарант.

22. Положение о государственном политическом управлении, принятом ВциК СССР 06.03.1922 // URL: https://www.alexanderyakovlev.org/fond/issuesdoc/1019309. 31.10.2021 
23. Конституция (Основной Закон) СССР : принята VIII съездом Советов СССР 5 дек. 1936 г // СПС Гарант.

24. Конституция (Основной Закон) Союза Советских Социалистических Республик: принята Верховным Советом СССР 7 окт. 1977 г // СПС Гарант.

25. Конституция (Основной Закон) РСФСР : принята Верховным Советом РСФСР 12 апр. 1978 года // СПС Гарант.

26. Закон СССР от 30.11.1979 N 1162-Х «О прокуратуре СССР» // СПС Гарант.

27. Федеральный закон от 17.01.1992 № 2202-1 (ред. от 01.07.2021) «О прокуратуре Российской Федерации» // СПС «Консультант плюс»

28. Указ Президента РФ от 05.12.2016 № 646 «Об утверждении Доктрины информационной безопасности Российской Федерации» // СПС

\section{References}

1. Manzhuyeva O.N. Fenomen informatsionnoy bezopasnosti: sushchnost' i osobennosti: dis. ... dokt. filosof. nauk: 09.00.11. - Ulan-Ude, 2015.

2. Istoriya zashchity informatsii v zarubezhnykh stranakh: uchebnoye posobiye/A.V. Babash, D.A. Larin. - M.: RIOR: INFRA-M, 2020.

3. Organy professional'nogo syska i inyye sub"yekty informatsionnoy bezopasnosti Rossiyskoy imperii: monografiya. / Yakovets Ye.N. - M.: Yurlit inform, 2012.

4. Polnoye sobraniye zakonov Rossiyskoy imperii. Sobraniye pervoye. 1649-1825 gg.: v 48 t. (PSZRI-1). SPb., 1830. T. 6. №№ 4409, 4418, 4481.

5. Polnoye sobraniye zakonov Rossiyskoy imperii. Sobraniye pervoye. 1649-1825 gg.: v 48 t. (PSZRI-1). SPb., 1830. T. 6 . № 3877.

6. Polnoye sobraniye zakonov Rossiyskoy imperii. Sobraniye pervoye. 1649-1825 gg.: v 48 t. (PSZRI-1). SPb., 1830. T. 6. № 3979.

7. Istoriya otechestvennoy prokuratury: uchebnoye posobiye / A. V. Yeromin. Sankt-Peterburg: Sankt-Peterburgskiy yuridicheskiy institut (filial) Universiteta prokuratury Rossiyskoy Federatsii, 2018.

8. Manifest ot 15 dekabrya $1763 \mathrm{~g}$. "Ob uchrezhdenii v Senate, vYustitsii, Votchinnoy i Revizion-Kollegiyakh Departamentov; o razdelenii po onym del" // SPS Garant

9. Polnoye sobraniye zakonov Rossiyskoy imperii. Sobraniye pervoye. 1649-1825 gg.: v 48 t. (PSZRI-1). SPb., 1830. T. 18. № 12932.

10. Karpenko S.V. Mikhail Khrushchev, Stepan Sheshkovskiy i «preobrazhen'ye» Taynoy kantselyarii v Taynuyu ekspeditsiyu/S.V. Karpenko//Novyy istoricheskiy vestnik. 2010. № 3. S. 57-94.

11. Organy professional'nogo syska i inyye sub"yekty informatsionnoy bezopasnosti Rossiyskoy imperii: monografiya /Yakovets Ye.N. - M.: Yurlit inform, 2012. - S. 181. 12. Polnoye sobraniye zakonov Rossiyskoy imperii. Sobraniye pervoye. 1649-1825 gg.: v 48 t. (PSZRI-1). SPb., 1830. T. 20. № 14392.

13. O postupanii yemu v otpravlenii sey dolzhnosti po instruktsiyam i ukazam; o bytii v yego vedenii Taynoy ekspeditsii i Komissii o sochinenii proyekta novogo ulozheniya i ob opredelenii Gosudarstvennogo kaznacheya dlya upravleniya Kazennoy chast'yu: ukaz imennoy, dannyy general-prokuroru 4 dek. 1796 g. // PSZRI-1. T. 24. № 17610. 14. Polnoye sobraniye zakonov Rossiyskoy imperii. Sobraniye pervoye. 1649-1825 gg.: v 48 t. (PSZRI-1). SPb., 1830. T. 27. № 20552.

15. Istoriya rossiyskoy prokuratury: kurs lektsiy / D.V. Kolykhalov; Un-t prokuratury Ros. Federatsii. - M., 2018. - 104 s.

16. Sudebnyye ustavy 20 noyabrya $1864 \mathrm{~g}$. za pyat'desyat let / V 2-kh tt. i dopoln. tom. - Pg., 1914. - 786+831+191 s.

17. Ulozheniye o nakazaniyakh ugolovnykh i ispravitel'nykh, s privedeniyem statey drugikh tomov Svoda zakonov, na kotoryye sdelany ssylki i ukazaniya v etom ulozhenii (izd. 1866 g.) // URL: https://dlib.rsl.ru/01003543887, data obrashcheniya 30.10.2021.

18. Gosudarstvennyye prestupleniya v Rossii v XIX veke: sb. polit. protsessov i dr. materialov, otnosyashchikhsya k istorii revolyuts. i oppozits. dvizheniy v Rossii / Sost. pod red. [i s predisl.] B. Bazilevskogo (V. Bogucharskogo). - SPb., 1904 - 1906. // URL: https:// elib.shpl.ru/ru/nodes/8400-t-3-protsess-193-h-spb-1904-russkaya-istoricheskayabiblioteka-7\#mode/inspect/page/7/zoom/4, data obrashcheniya 30.10.2021.

19. Polozheniye o merakh k okhraneniyu gosudarstvennogo poryadka i obshchestvennogo spokoystviya: polozheniye Komiteta ministrov, vysochayshe utverzhdennoye 14 avg. $1881 \mathrm{~g}$. // PSZRI-3. T. 1. № 350.

20. Postanovleniye VTSIK ot 28.05.1922 "Polozheniye o prokurorskom nadzore" // SPS Konsul'tantPlyus.

21. Konstitutsiya (Osnovnoy Zakon) Soyuza Sovetskikh Sotsialisticheskikh Respublik (utverzhdena rezolyutsiyey II-go S"yezda Sovetov Soyuza SSR ot 31 yanvarya 1924 g. ) // SPS Garant.

22. Polozheniye o gosudarstvennom politicheskom upravlenii, prinyatom VTSIK SSSR 06.03.1922 // URL: https://www.alexanderyakovlev.org/fond/issues-doc/1019309. 31.10.2021.

23. Konstitutsiya (Osnovnoy Zakon) SSSR: prinyata VIII s"yezdom Sovetov SSSR 5 dek. $1936 \mathrm{~g} / /$ SPS Garant.

24. Konstitutsiya (Osnovnoy Zakon) Soyuza Sovetskikh Sotsialisticheskikh Respublik: prinyata Verkhovnym Sovetom SSSR 7 okt. 1977 g // SPS Garant. 
25. Konstitutsiya (Osnovnoy Zakon) RSFSR: prinyata Verkhovnym Sovetom RSFSR 12 apr. 1978 goda // SPS Garant.

26. Zakon SSSR ot 30.11.1979 N 1162-X "O prokurature SSSR" // SPS Garant.

27. Federal'nyy zakon ot 17.01.1992 № 2202-1 (red. ot 01.07.2021) "O prokurature Rossiyskoy Federatsii" // SPS «Konsul'tant plyus»

28. Ukaz Prezidenta RF ot 05.12.2016 № 646 “Ob utverzhdenii Doktriny informatsionnoy bezopasnosti Rossiyskoy Federatsii" // SPS

Соколов Илья Александрович, аспирант Московского государственного юридического университета имени О.Е. Кутафина (МГЮА), кафедра организации судебной и прокурорско-следственной деятельности.; старший помощник Щелковского городского прокурора Московской области. 107996, Москва, Малый Кисельный переулок, д. 5. E-mail: sokolovilyapilot@ mail.ru

SOKOLOV Ilya Aleksandrovich, post-graduate student of the Moscow State Law University named after O.E. Kutafina (Moscow State Law Academy), Department of Organization of Judicial and Prosecutorial Investigative Activities. 125993, Moscow, Sadovaya-Kudrinskaya St., 9. Assistant to the Shchelkovo City Prosecutor of the Moscow Region. 107996, Moscow, Maly Kiselny lane, 5. E-mail: sokolovilyapilot@mail.ru 